Check for updates

Cite this: RSC Adv., 2017, 7, 27248

Received 13th March 2017

Accepted 11th May 2017

DOI: 10.1039/c7ra03014b

rsc.li/rsc-advances

\section{Utilization of Euryale ferox Salisbury seed shell for removal of basic fuchsin dye from water: equilibrium and kinetics investigation $\uparrow$}

\author{
S. Kalita, ${ }^{\text {a M. Pathak, }}{ }^{\text {a }}$ G. Devi, ${ }^{a}$ H. P. Sarma, ${ }^{\text {b }}$ K. G. Bhattacharyya, ${ }^{1 D}{ }^{\text {c }}$ A. Sarma ${ }^{d}$ \\ and A. Devi iD *a
}

Euryale ferox Salisbury (E. ferox) is an environmentally and economically important wetland macrophyte. This paper investigates the adsorption of a carcinogenic dye, basic fuchsin in the aqueous phase onto the hard shell of Euryale ferox seeds so as to establish the thrown away residue as a novel, efficient, biofriendly and economically low-cost alternative adsorbent against other expensive adsorbents. Characterization of the bioadsorbent was carried out by TGA, SEM, FTIR and Zetasizer analyses. Zeta potential analysis showed good stability of the biomaterial around neutral $\mathrm{pH}$. The operating variables such as adsorbent amount, adsorbate concentration, contact time, $\mathrm{pH}$ and temperature were optimized in a batch system. The maximum biosorption capacity of $E$. ferox was found to be $19.48 \mathrm{mg} \mathrm{g}^{-1}$ which could remove as much as $97.4 \%$ of the dye from an aqueous solution of concentration $40 \mathrm{mg} \mathrm{L}^{-1}$ at 298 K. Isothermal and kinetic data fitted best to Freundlich and pseudo second order models respectively. The thermodynamic study revealed the exothermic and spontaneous nature of the adsorption process.

\section{Introduction}

Dyes have always been an integral part of human civilization, whether for dyeing cloth, leather, and hair or as a coloring agent for food. In the last few decades with the surge in human population and economic development, there has been a tremendous development of the synthetic dye industries for meeting the demand for higher supply and better quality of dye. This expansion has resulted in a simultaneous increase in the liquid effluent generated from the synthetic dye manufacturing and user industries. It is estimated that annually more than 1.5 $\times 10^{8} \mathrm{~m}^{3}$ of colored effluents is discharged as waste water. ${ }^{1}$

The discharged wastewater enters the local water bodies and disturbs the aquatic ecosystem by influencing the physicochemical parameters of water which are known for contributing to the maintenance of the ecosystem, essential for the dwelling aquatic organisms. Since most of the dyes are suspected to be carcinogenic and mutagenic in nature, they

${ }^{a}$ Environmental Chemistry Laboratory, Resource Management and Environment Section, Life Science Division, Institute of Advanced Study in Science and Technology, Guwahati, Assam, India. E-mail: deviarundh2@yahoo.co.in; Fax: +91 3612273062; Tel: +913612912075 ext. 118

${ }^{b}$ Department of Environmental Science, Gauhati University, Guwahati, Assam, India

${ }^{c}$ Department of Chemistry, Gauhati University, Guwahati, Assam, India

${ }^{d}$ Department of Chemistry, Morigaon College, Morigaon 782105, Assam, India

$\dagger$ Electronic supplementary information (ESI) available. See DOI: 10.1039/c7ra03014b have the potential to bring toxicity in human beings, fish species and microorganisms. ${ }^{2,3}$

Basic fuchsin (MF: $\mathrm{C}_{20} \mathrm{H}_{20} \mathrm{CIN}_{3}$, MW: 337.85) a cationic dye consisting of the salts (hydrochloride or acetate) of rosaniline and pararosaniline with triaminotriphenylmethane as its chemical structural body is widely used as a coloring agent for textile and leather industries. It is also used as a biological stain for nucleus, tissues, and muscles and as a tracking dye for certain proteins. ${ }^{4,5}$ On direct contact with skin or when ingested or inhaled the dye may cause severe health hazards like irritation to skin or respiratory or gastrointestinal tract. ${ }^{5}$ The suspected carcinogenic, mutagenic and target organ effects of this dye on humans gives the reason to develop a competent and efficient material or a method for tackling and efficiently removing this pollutant. Several conventional techniques such microbiological or enzymatic decomposition, oxidation, coagulation, flocculation, chemical degradation, electroplating, membrane filtration, etc. ${ }^{6,7}$ have been developed and used till now. But among these available techniques, the biosorption technology has emerged as a more attractive and greener alternative to the typical treatment tactics employed for decolourization of effluents due to its modest design, smooth operation and most importantly its potential cost-effectiveness. For removal of basic fuchsin, only a few adsorbents have been developed till now namely peat-resin particle, ${ }^{8}$ Aspergillus niger dead biomass, ${ }^{9}$ bottom ash and deoiled soya, ${ }^{5} \mathrm{KMnO}_{4}$-modified activated carbon from Typha orientalis, ${ }^{10}$ mussel shell ${ }^{11}$ etc. The present study aims to utilize a novel waste material capable of removing dye material as 
a model experiment so as to boost the emerging field of bioremediation through the adsorption strategy. The prepared material is the seed coat of Euryale ferox Salisbury (Nymphaeaceae family), locally famous as "Makhana". It was reported that E. ferox known for its nutritional and medicinal properties is well distributed in the tropical and subtropical regions of Southeast and East Asia. ${ }^{12}$ In India, it is found in the shallow water bodies of North Bihar and lower Assam regions of India. ${ }^{12}$ E. ferox seed cover was chosen as a dye removal bioadsorbent because it is an easily available and unused biorefuse of the edible part of the plant. Even though other biomaterials have been used for removal of basic fuchsin, this macrophytic bio-waste has remained unexplored as a source for remediating wetland water bodies polluted with colored effluents. Relevant kinetic and adsorption isotherm models were employed for a better understanding of this unique adsorbent performance. As the material is sufficiently found to be flourishing in the wetland, there is a greater chance of using this adsorbent for remediating a wetland polluted with anthropogenic activities.

The concentrations of dyes and pigments in industrial effluents are not well documented and the concentrations vary depending on the nature of the industry, the amount of dyes used, the efficiency of the effluent treatment procedures, etc. The present experiments can be considered as a kind of model in which a comparatively wide range of dye concentrations was used with a view to having results of general utility. The adsorbent amounts were similarly selected to achieve optimum adsorption and removal of the dyes.

\section{Experimental}

\subsection{Collection and preparation of the adsorbent and adsorbate}

Fresh fruits of $E$. ferox were collected from the wetland Deepor Beel (a Ramsar site) of Assam, India. The separated seeds from the harvested fruits were washed and shade dried. The seed coat to be utilized as an adsorbent was then removed from the dried seeds and was again washed, air-dried and ground into a powdered form. It was further sieved in between the fraction range of $75-200 \mu \mathrm{m}$ and was repeatedly washed with Millipore water to obtain color and turbidity-free washings. The washed seed powder fractions were first dried at room temperature for 48 hours and then oven dried at $50{ }^{\circ} \mathrm{C}$ temperature to a constant weight. It was then made moisture free in a desiccator until its further use. The basic fuchsin dye taken for the experiment purpose was of analytical grade purchased from Sigma-Aldrich. A stock solution of 500 ppm was prepared by dissolving weighed amount of powdered dye in distilled water. A calibration curve was obtained by measuring the optical density of different known dye concentrations at $542 \mathrm{~nm}$ using a UV-Vis spectrophotometer (Shimadzu 1601, Japan). ${ }^{13}$ Chemdraw Ultra 8.0 software was used for the construction of the chemical structure of the dye. The chemical structure of the dye is as follows:

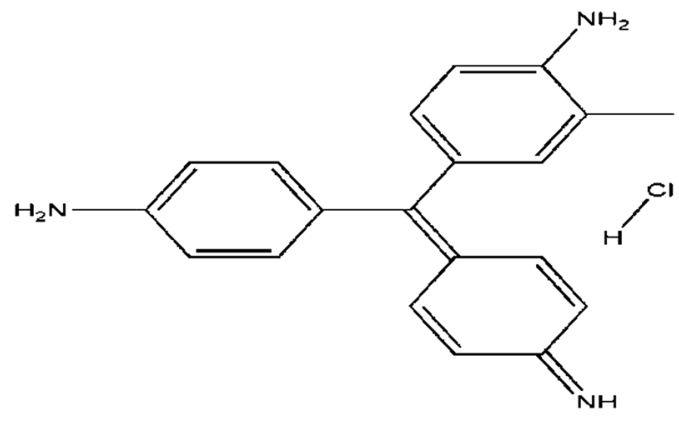

Chemical Structure of Basic fuchsin

\subsection{Characterization of the adsorbent biomaterial}

Gravimetric analysis for the determination of moisture content, organic matter and organic carbon of the biomaterial was done in a muffle furnace following the AOAC 2000 protocol $^{\mathbf{1 4}}$ and were calculated using the following equations:

$$
\begin{gathered}
\% \text { Ash content }=\frac{\text { ash weight }}{\text { dry weight }} 100 \\
\% \text { Organic matter }=\frac{\text { dry weight }- \text { ash weight }}{\text { dry weight }} 100 \\
\% \text { Organic carbon }=\frac{\text { organic matter } \%}{1.724}
\end{gathered}
$$

The biomass was treated prior to the determination of its lignocellulosic components following the TAPPI method. ${ }^{\mathbf{1 5 , 1 6}}$ The treated biomass is considered to comprise of cellulose, hemicellulose, lignin and extractives. Thermal gravimetric analysis (TGA) was carried out using Perkin Elmer TGA 4000 at a heating rate of $10{ }^{\circ} \mathrm{C}$ per minute with $\mathrm{N}_{2}$ flow rate of $20 \mathrm{~mL}$ $\min ^{-1}$. CHNS analyser (EuroEA3000 Elemental Analyser) and Atomic Absorption Spectrophotometer (Shimadzu AA 7000) was used for ultimate and element analysis respectively. The surface topography of the biomaterial was analyzed by using Field Emission Scanning Electron Microscope i.e. FE-SEM (Zeiss, $\Sigma$ Sigma, Germany). The Fourier Transform Infrared Spectrophotometer (NICOLET 6700, USA) was used to record the spectra in transmission mode within the range of 4000-500 $\mathrm{cm}^{-1}$ to investigate about the functional groups of the adsorbent by employing the $\mathrm{KBr}$ pellet method. The surface charge of the adsorbent solution was determined by recording zeta potential measurements of the solution using the Malvern Zetasizer Nano series, Nano-ZS90. Same instrumental analyses were performed for evaluating the potential changes occurred in the biomaterial after the adsorption of the subject dye.

\subsection{Bioadsorption procedure}

The adsorption experiments were carried out in a series of the batch to evaluate the percentage removal and adsorption capacity of the material. The parameter variation experiments 
were operated in $100 \mathrm{~mL}$ Erlenmeyer flasks with a $50 \mathrm{~mL}$ test dye solution placed in a thermostatic shaker at $120 \mathrm{rpm}$ for agitation. The effect of the adsorbent amount, adsorbate strength, contact time and temperature were inspected by varying each parameter value at the natural $\mathrm{pH}$ of the working solution. The $\mathrm{pH}$ of the $\mathrm{BF}$ aqueous solution did not change much with dilution and was found to be between 6.0-6.5. Therefore, the effect of the $\mathrm{pH}$ variation on the adsorption of test solution of varying concentration was studied after the optimization of other parameters. The $\mathrm{pH}$ was adjusted using $0.1 \mathrm{~N} \mathrm{NaOH}$ and $0.1 \mathrm{~N} \mathrm{HCl}$ solutions. The equilibrium reached a concentration of BF solution was centrifuged and then analysed at $542 \mathrm{~nm}$. Compared to inorganic heavy materials, the biosorbent settles down slowly, but complete settlement could be achieved without much difficulty. The obtained results were used to calculate the equilibrium adsorption capacity $q_{\mathrm{e}}\left(\mathrm{mg} \mathrm{g}^{-1}\right)$ and the percentage removal by applying the following equations:

$$
\begin{gathered}
q_{\mathrm{e}}=\left\{\left(C_{\mathrm{o}}-C_{\mathrm{e}}\right) V\right\} / M \\
\text { Dye removal }(\%)=\left\{C_{\mathrm{o}}-C_{\mathrm{e}} / C_{\mathrm{o}}\right\} \times 100
\end{gathered}
$$

where $C_{\mathrm{o}}$ and $C_{\mathrm{e}}\left(\mathrm{mg} \mathrm{L}^{-1}\right)$ represents the initial and the equilibrium concentration of the dye solution respectively, $V(\mathrm{~L})$ is the volume of the dye solution, and $M(\mathrm{~g})$ is the mass of the sorbent added.

In the present study, the adsorption data were subjected to different isotherm and kinetic models for examining and understanding the mechanistic steps and surface chemistry involved in the adsorption process. The thermodynamic behaviour was also extensively studied. The details of the models and equations used are given in the appendix. All the experiments were performed in triplicates and the standard error (SE) values are mentioned in the figures and tables.

\section{Results and discussion}

\subsection{Characterization of $E$. ferox}

3.1.1 Compositional analysis of the adsorbent. The gravimetric analysis following the AOAC 2000 protocol $^{14}$ revealed the inorganic content (ash content), organic matter and organic carbon of E. ferox pericarp as $0.4,99.6$ and $55.77 \%$ respectively. The obtained TGA graph (Fig. 1) elucidates the thermal behaviour and thermal stability of the bioadsorbent by plotting the increase or decrease in the weight percentage of the biomaterial against the gradual increase in temperature (from room temperature to $1000{ }^{\circ} \mathrm{C}$ ). The TGA graph shows an initial $7 \%$ weight loss below $100^{\circ} \mathrm{C}$ and no loss of weight up to $250^{\circ} \mathrm{C}$. The initial weight loss corresponds to the loss of moisture present in the bioadsorbent. ${ }^{17}$ A major decomposition of $52 \%$ between 250 and $330{ }^{\circ} \mathrm{C}$ as seen in the graph can be attributed to the thermal decompositions of hemicelluloses, cellulose, lignin and pectin. ${ }^{18}$ Another decomposition at $330{ }^{\circ} \mathrm{C}$ to $500{ }^{\circ} \mathrm{C}$ corresponds to residual lignin, cellulose, pectin and hemicelluloses in the adsorption study of methylene blue by Citrullus lanatus rind. ${ }^{19}$ Around $5 \%$ remnants after $500{ }^{\circ} \mathrm{C}$ accounts for the ash content of the biomaterial. The absence of noteworthy changes

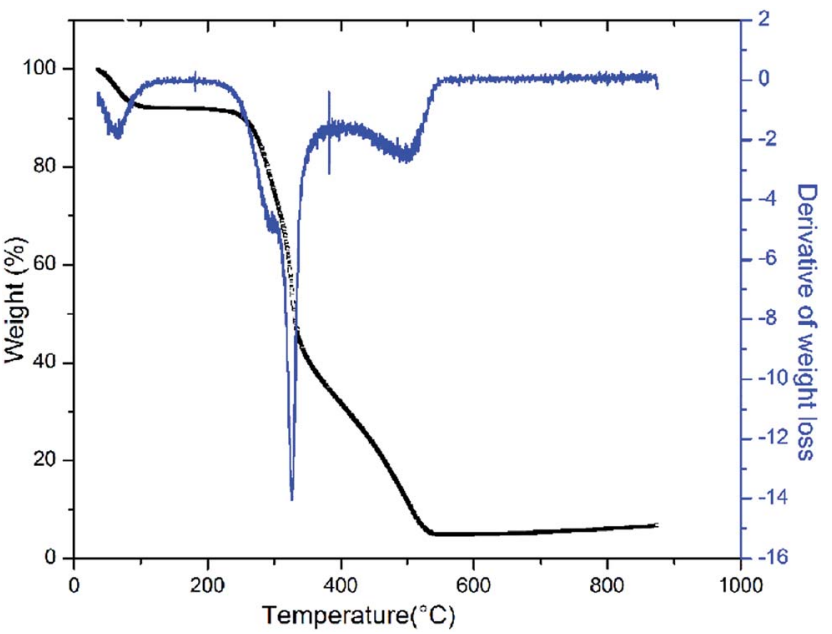

Fig. 1 TGA-DTG graph of E. ferox.

above $600{ }^{\circ} \mathrm{C}$ indicates the optimum carbonization temperature to be around $600{ }^{\circ} \mathrm{C}$. From the DTG curve, the primary decomposition temperatures for the E. ferox were found to be $67,295,325$ and $500{ }^{\circ} \mathrm{C}$ respectively.

The TGA result regarding the presence of different lignocellulosic constituents was confirmed by gravimetric analysis. The cellulose, hemicellulose lignin and extractives amount was determined in percentage as $14.4 \%, 38.9 \%, 42.5 \%$ and $4.2 \%$. The presence of high lignin content in the shell is responsible for the protection of interior portion of the seed. On an average nutshells tend to contain more lignin content than the other lignocellulosic constituents. ${ }^{20}$ The amount of lignin found in this work is the higher when compared to cellulose and hemicellulose in coconut shell (46\%) as reported by Cagnon et al. ${ }^{21}$ respectively. Apart from investigating the thermal behaviour of the adsorbent, the TGA technique could also be used for proximate analysis of the material. The results of proximate analysis and ultimate analysis are given in Table 1 . The differences in the ash content analysis using simple gravimetric analysis $(0.4 \%)$ in a muffle furnace and by TGA (5\%) arose because of the loss in fly ash and other volatile matter during the open heating of the sample in the muffle furnace.

The proximate and ultimate analysis result were in accordance to the reported literature by Kumar and Jena. ${ }^{22}$ The determined values of trace elements like potassium, magnesium, zinc, copper, manganese, sodium, calcium and phosphorus are given in Table 2. According to Ekpete and Horsfall, ${ }^{23}$

Table 1 Composition of $E$. ferox (mean $\pm \mathrm{SE}$ )

\section{Proximate}

content (in \%)

Moisture content

Ash content

Volatile matter

Fixed carbon
$7 \pm 0.03$

$5 \pm 0.41$

$69 \pm 0.01$

$19 \pm 0.02$
Ultimate content (\%)

Carbon Hydrogen Nitrogen Sulphur Oxygen
$43.82 \pm 0.31$

$4.1 \pm 0.01$

$0.81 \pm 0.01$

$0.06 \pm 0.07$

$51.21 \pm 0.49$ 
Table 2 Elemental composition of E. ferox (mean $\pm \mathrm{SE}$ )

Elemental analysis (in $\mathrm{mg} \mathrm{kg}^{-1}$ )

Potassium

Calcium

Magnesium

Sodium

Zinc

Manganese

Copper

Phosphorus

the low ash content and low moisture is an indicative that the raw material can be used as a bioadsorbent. Therefore, E. ferox is an excellent raw material to be put into use as a bioadsorbent.

3.1.2 Surface topographical study. Morphological changes are always easier to compare and elucidate the differences between a treated and untreated samples. Therefore, we used phase contrast microscope and scanning electron microscope to examine the changes before and after the dye adsorption process. The adsorption of the dye can be clearly distinguished from the control and test microscopic images of $E$. ferox in the ESI (Fig. 1Sa and $\mathrm{b} \dagger$ ). The scanning electron micrographs of the biomaterial before and after adsorption of the dye was obtained at $95 \mathrm{k} \times$ and $10 \mathrm{k} \times$ magnifications respectively (Fig. 1Sc and $\mathrm{e} \dagger$ ) The observations of the natural biomaterial before adsorption made it evident that the powdered form of $E$. ferox has an amorphous plane containing cavity structures which could have the ability to adhere dye particles on its exposed surface area. The void-free smoother topography of the biomaterial after the adsorption process implies the adherence of polygonal dye particles to the surface. ${ }^{24}$ Such topographical changes on biomaterial surface after adsorption of dye have also been reported in earlier adsorption studies. ${ }^{24,25}$ The Energy Dispersive $\mathrm{X}$-ray (EDX) image (Fig. 1Sd and $\mathrm{f}_{\dagger} \dagger$ ) further supports the occurrence of dye adsorption on the adsorbent surface since the $\mathrm{Cl}$ element peak of the dye compound appears along with the other constituent peaks such as $\mathrm{Na}, \mathrm{K}, \mathrm{Mg}, \mathrm{Ca}, \mathrm{C}, \mathrm{O}$ after the adsorption.

3.1.3 FTIR study of bioadsorption. FTIR spectroscopy was carried out for identifying the functional groups involved in the adsorption process by investigating the vibrational properties of the material before and after adsorption of the dye. The FTIR spectra of the pure dye and biomaterial before and after adsorption are shown in Fig. 2. The FTIR spectra before adsorption shows a broad absorption band around 3372.61

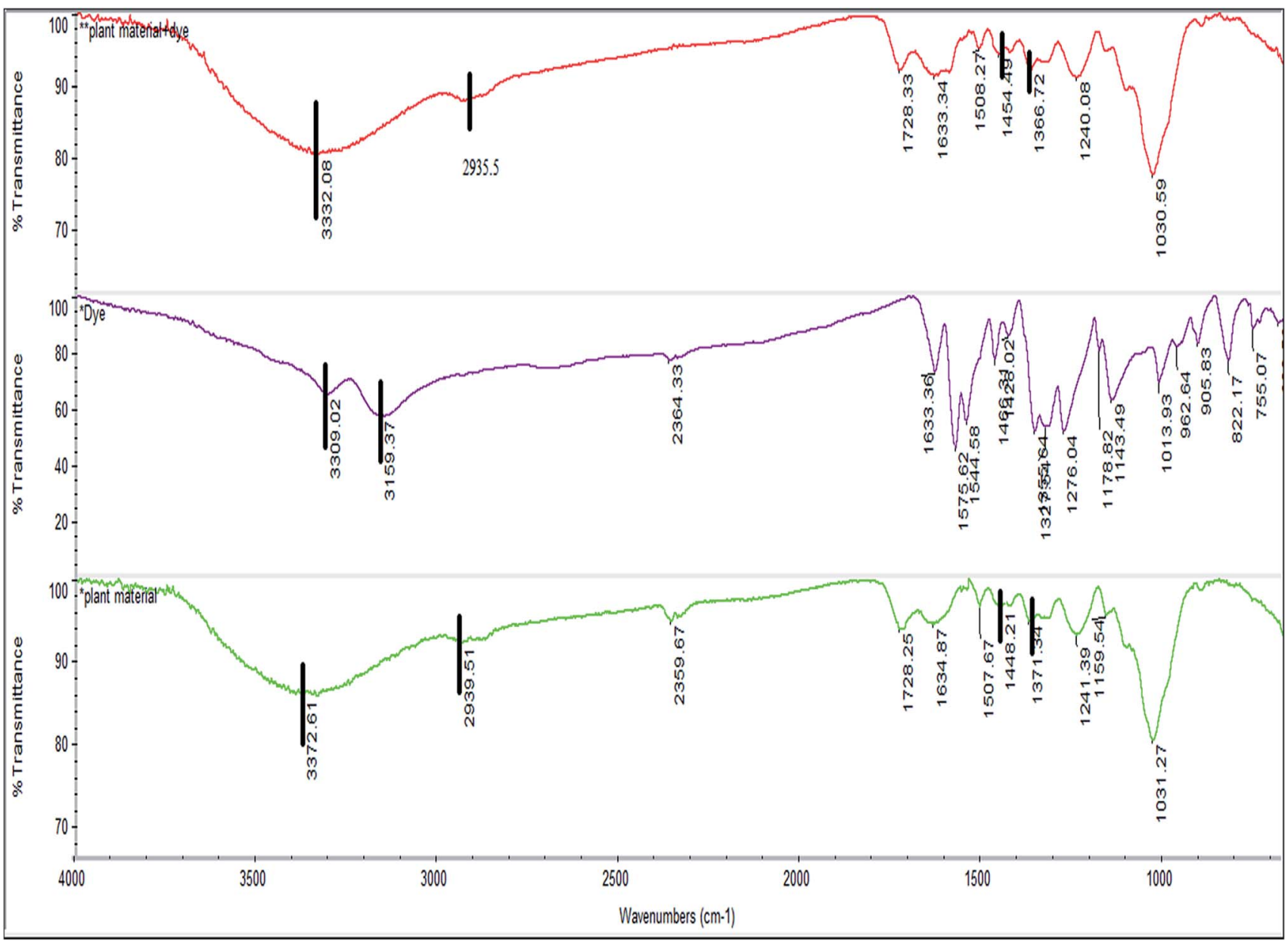

Fig. 2 FTIR spectra of pure dye $(-)$, E. ferox before $(-)$ and after $(\rightarrow)$ dye adsorption. 
$\mathrm{cm}^{-1}$ which corresponds to the $-\mathrm{OH}$ group of alcoholic compounds of E. ferox. ${ }^{3}$ However, this band shifted from 3372.61 to $3332.08 \mathrm{~cm}^{-1}$ along with the decrease in the percentage transmittance of the peak after the adsorption of the dye. Simultaneously it was observed that the doublet due to primary amine $\left(-\mathrm{NH}_{2}\right)$ and secondary amine $(-\mathrm{NH})$ appearing at 3309.0 and $3159.3 \mathrm{~cm}^{-1}$ as observed in the FTIR spectra of the dye, which were likely to have been masked by the $\mathrm{OH}$ band.

This might be an indication that E. ferox and BF interactions take place through these functional groups. The symmetric and asymmetric vibrational modes of methyl $\left(-\mathrm{CH}_{3}\right)$ and methylene $\left(\mathrm{CH}_{2}\right)$ groups showed a small shift from 2939.5 to $2935.5 \mathrm{~cm}^{-1}$ after adsorption of the dye which might suggest participation of these groups also in taking up the dye molecules. ${ }^{26}$ The bands at 1448.2 and $1371.3 \mathrm{~cm}^{-1}$ in the spectra of the biomaterial can be attributed to $\mathrm{C}-\mathrm{O}$ stretching of carboxylic or carbonate group and the bending vibrations of $\mathrm{C}-\mathrm{H}$ or $\mathrm{OH}$ groups respectively. ${ }^{25}$ After adsorption of the dye, a shift was recorded in these wave numbers from 1448.2 to $1454.5 \mathrm{~cm}^{-1}$ and 1371.3 to $1366.7 \mathrm{~cm}^{-1}$ confirming the involvement of those functional groups in binding the dye to $E$. ferox surface. The FTIR results suggest that the binding of the BF dye to the bioadsorbent surface may have occurred mainly due to interactions between $\mathrm{OH}$ groups of $E$. ferox and $\mathrm{NH} / \mathrm{NH}_{2}$ groups of the dye. The presence of hydroxyl and carboxyl groups in the FT-IR spectra, further, establishes the anionic nature of the bioadsorbent. Therefore, these groups are likely to serve as the binding sites for the cationic dye. ${ }^{3}$ Similar results were previously observed for adsorption of dyes on cupuassu shell. ${ }^{27}$
3.1.4 Surface charge study. Zeta potential measurements were carried out to measure the biomaterial stability for the $\mathrm{pH}$ range of 1-10 (Fig. 3). The surface charge of E. ferox varied from +0.115 to $-29.400 \mathrm{mV}$ with its isoelectric point lying nearby at $\mathrm{pH}$ 1.5. The biomaterial can be considered as negatively charged almost throughout the entire pH-range with much more negative charges in the $\mathrm{pH}$ range of 6.0-8.0. This complies with the observed stability of the biomaterial indicating that it will not aggregate over time and almost the entire surface will be available for adsorption of cations. ${ }^{25}$

\subsection{Effects of various parameters on adsorption}

3.2.1 Effects of $\mathbf{p H}$. The $\mathrm{pH}$ of the working solution is known for its effect on the efficiency of the adsorption process since the charges of adsorbent materials and adsorbate molecules might be changed by solution $\mathrm{pH}$ affecting the functional groups on the active sites of the adsorbent and the structure of the adsorbate molecules. ${ }^{19}$ It was found that the dye is sensitive to higher $\mathrm{pH}$ because the color intensity of the solution changed when subjected to $\mathrm{pH}>6.0$. A similar observation was made for the methylene blue dye when subjected to a higher alkaline condition..$^{3,28}$ Therefore, the influence of $\mathrm{pH}$ on the adsorption of BF by E. ferox was studied at pH 2.0, 4.0 and 6.0 at a constant temperature $(308 \mathrm{~K})$, dye concentration $\left(40 \mathrm{mg} \mathrm{L}^{-1}\right)$ and adsorbent amount $\left(2.0 \mathrm{~g} \mathrm{~L}^{-1}\right)$. An increase in the dye removal efficiency was recorded from $48.67 \%$ to $96.73 \%$ for the $\mathrm{pH}$ variation with a maximum uptake of the dye at $\mathrm{pH}$ 6.0. The surge in the cationic dye adsorption when subjected to higher $\mathrm{pH}$ can be attributed to the increasingly negative adsorbent surface. At very low $\mathrm{pH}$, the surface negative charge is not much

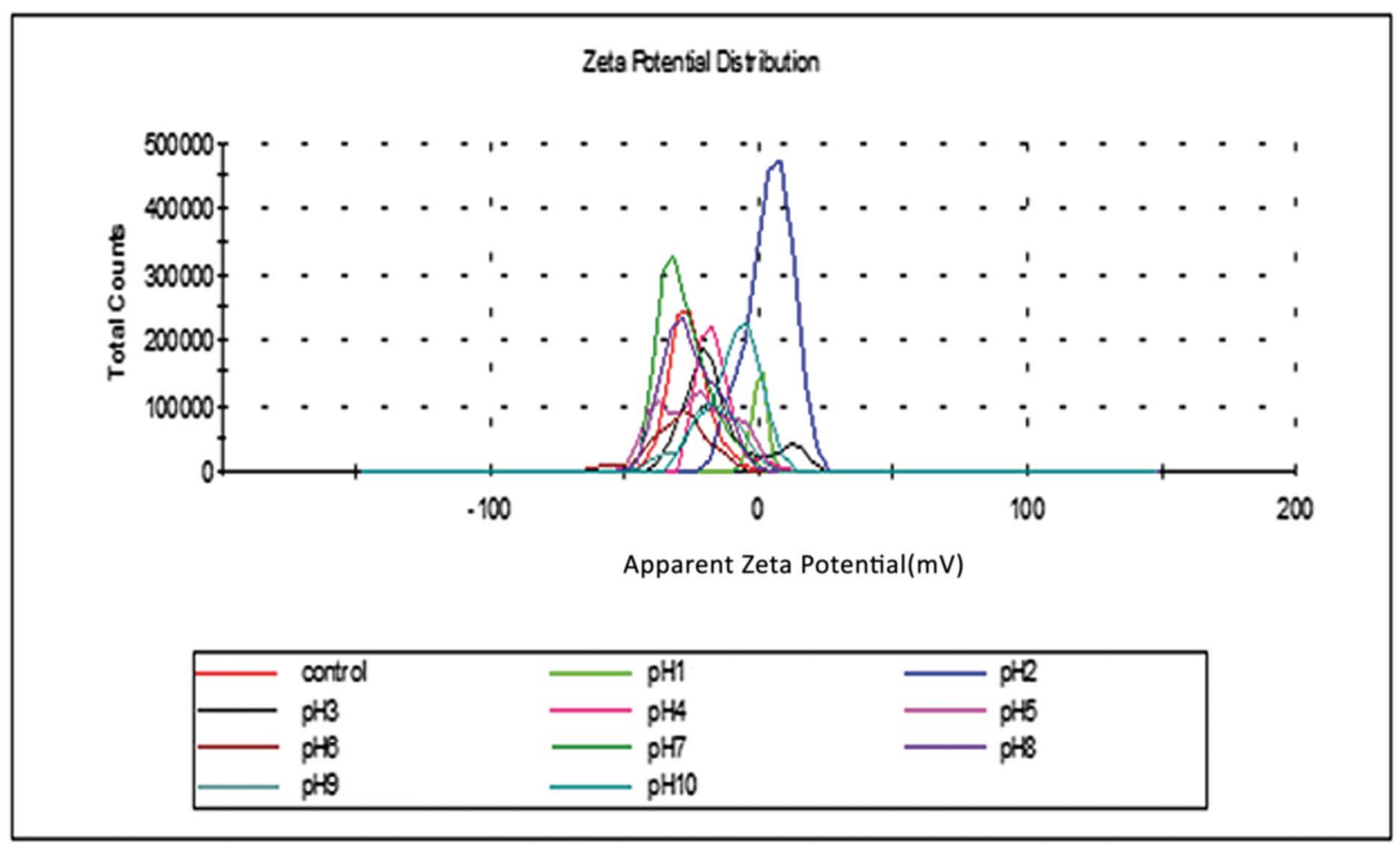

Fig. 3 Surface charge analysis of E. ferox. 


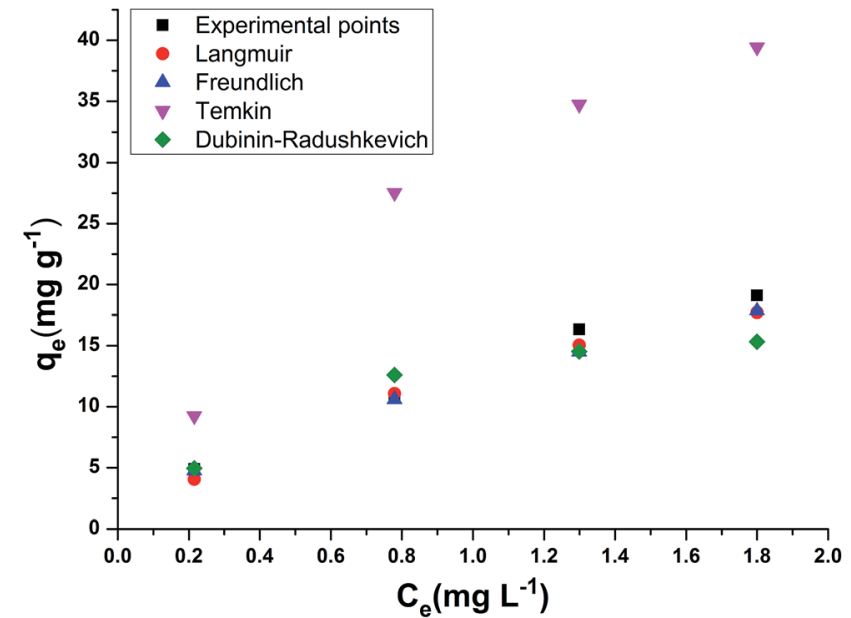

Fig. 4 General isotherm plots of experimental and calculated model points.
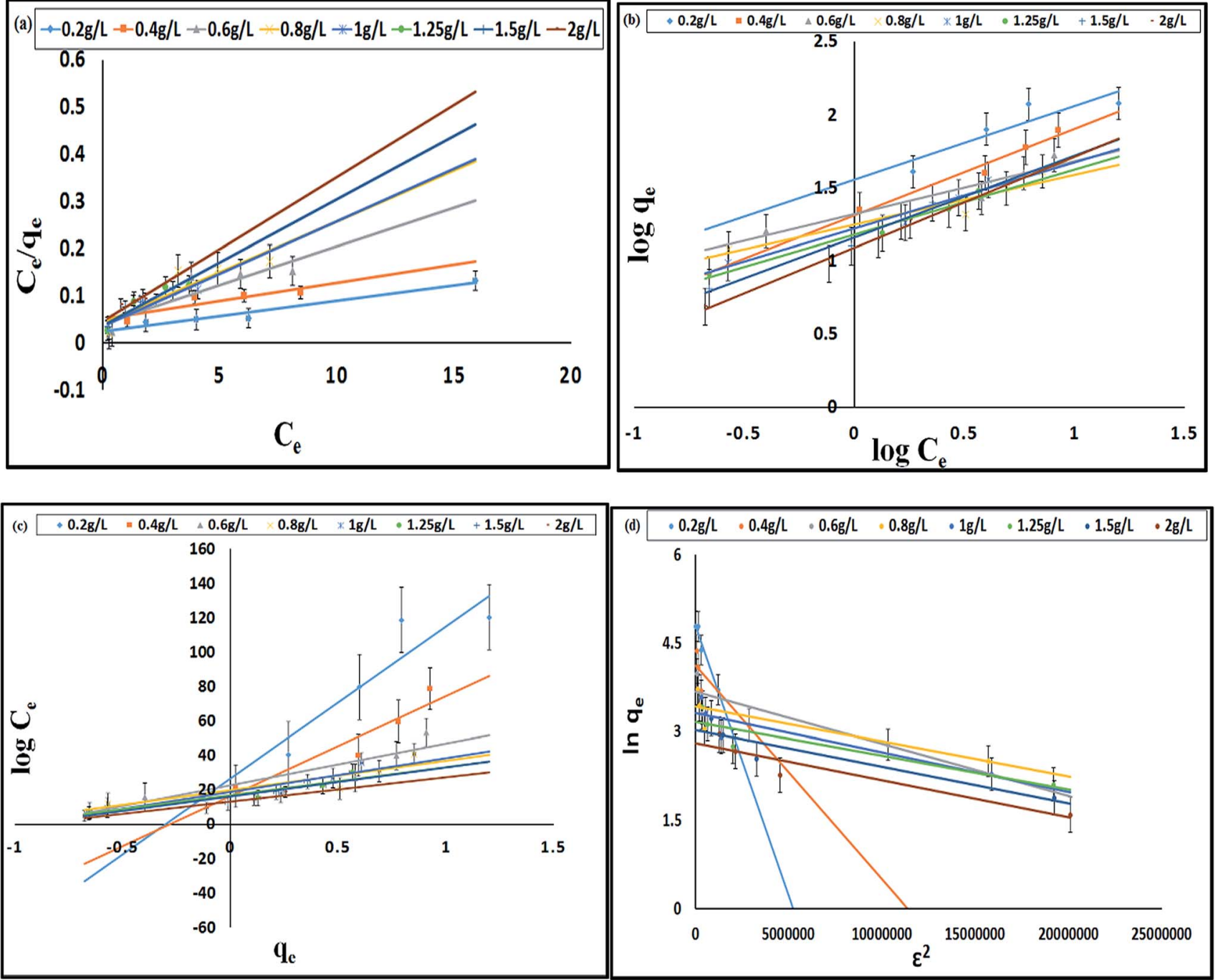

Fig. 5 Isotherm models for BF adsorption on E. ferox: (a) Langmuir; (b) Freundlich; (c) Temkin; (d) Dubinin-Radushkevich (experimental conditions: initial BF concentration $=40 \mathrm{mg} \mathrm{L}^{-1}$, temperature $=308 \mathrm{~K}, \mathrm{pH}=6$ ) (mean \pm standard error). as observed from zeta potential measurements and therefore, the material does not have a strong affinity for the cationic dye ions. This results in a lower adsorption rate. ${ }^{25}$

3.2.2 Effects of adsorbent dosage and dye concentration. The effects of varying adsorbent dosages ( 0.2 to $\left.2.0 \mathrm{~g} \mathrm{~L}^{-1}\right)$ and different dye concentration (10 to $40 \mathrm{mg} \mathrm{L}^{-1}$ ) were investigated on dye percentage removal at $308 \mathrm{~K}$ temperature. The results showed that the adsorption was less for elevated dye concentration and more for elevated adsorbent loadings. The increased dye percentage removal from 60.25 to $95.5 \%$ with an increase in E. ferox amount $\left(0.2\right.$ to $\left.2.0 \mathrm{~g} \mathrm{~L}^{-1}\right)$ for a fixed dye concentration $\left(40 \mathrm{mg} \mathrm{L}^{-1}\right)$ could be attributed to the increase in the number of adsorption sites and the available sorption surface for decolourization. ${ }^{25}$ Contrastingly, the increase in $\mathrm{BF}$ concentration for a fixed adsorbent amount $\left(2 \mathrm{~g} \mathrm{~L}^{-1}\right)$ resulted a decline in the dye percentage removal from 92.79 to $87.50 \%$ as the increasing number of $\mathrm{BF}$ molecules had to compete for a constant number of available active adsorption sites on the biosorbent surface. ${ }^{\mathbf{1 9 , 2 5}}$ 
Table 3 Biosorption capacity of various bioadsorbents for BF dye from the literature

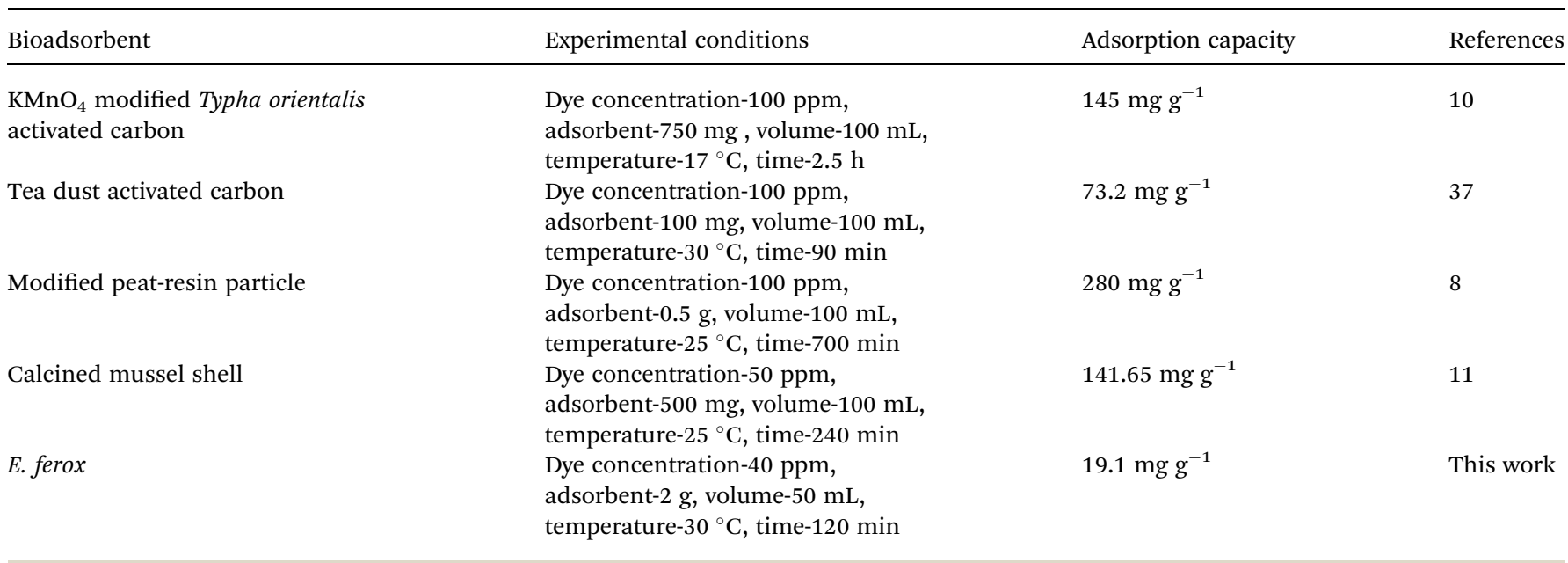

3.2.3 Adsorption isotherm study. The experimental data obtained at equilibrium is graphically represented by adsorption isotherm models so as to describe the adsorption process by understanding the adsorbate-adsorbent interaction. Fig. 4 shows the general isotherm plot of experimental and calculated model points for adsorption of basic fuchsin dye on E. ferox.

The models which were applied to fit the equilibrium data are Langmuir, Freundlich, Temkin and Dubinin-Radushkevich whose plots at a temperature of $308 \mathrm{~K}$ are presented in Fig. 5ad respectively. Table 3 shows the comparison of adsorption capacity of various bioadsorbents along with the present work. Most of the adsorbents are either modified or in activated carbon form, thereby, having higher $q_{\mathrm{e}}$ than $E$. ferox. The values obtained for the different isotherm parameters along with the correlation coefficient are listed in Table 4. The $r^{2}$ values of Freundlich isotherm in comparison to other two models were found to be more close to 1 suggesting that the Freundlich model anticipates the adsorption behaviour of the BF dye better on E. ferox.

The Langmuir isotherm model assumption is about monolayer coverage of the liquid phase concentration of the dye on a solid surface of the adsorbent in such a way that all the binding sites for the adsorption are equivalent and the surface is uniform with no interactions between adsorbed molecules. ${ }^{29}$ The monolayer biosorption capacity $\left(q_{\mathrm{m}}\right)$ was calculated to be $32.67-$

Table 4 Isotherm parameter values of adsorption of BF (10-40 $\mathrm{mg} \mathrm{L}^{-1}$ ) on E. ferox at $308 \mathrm{~K}$ (mean \pm standard error)

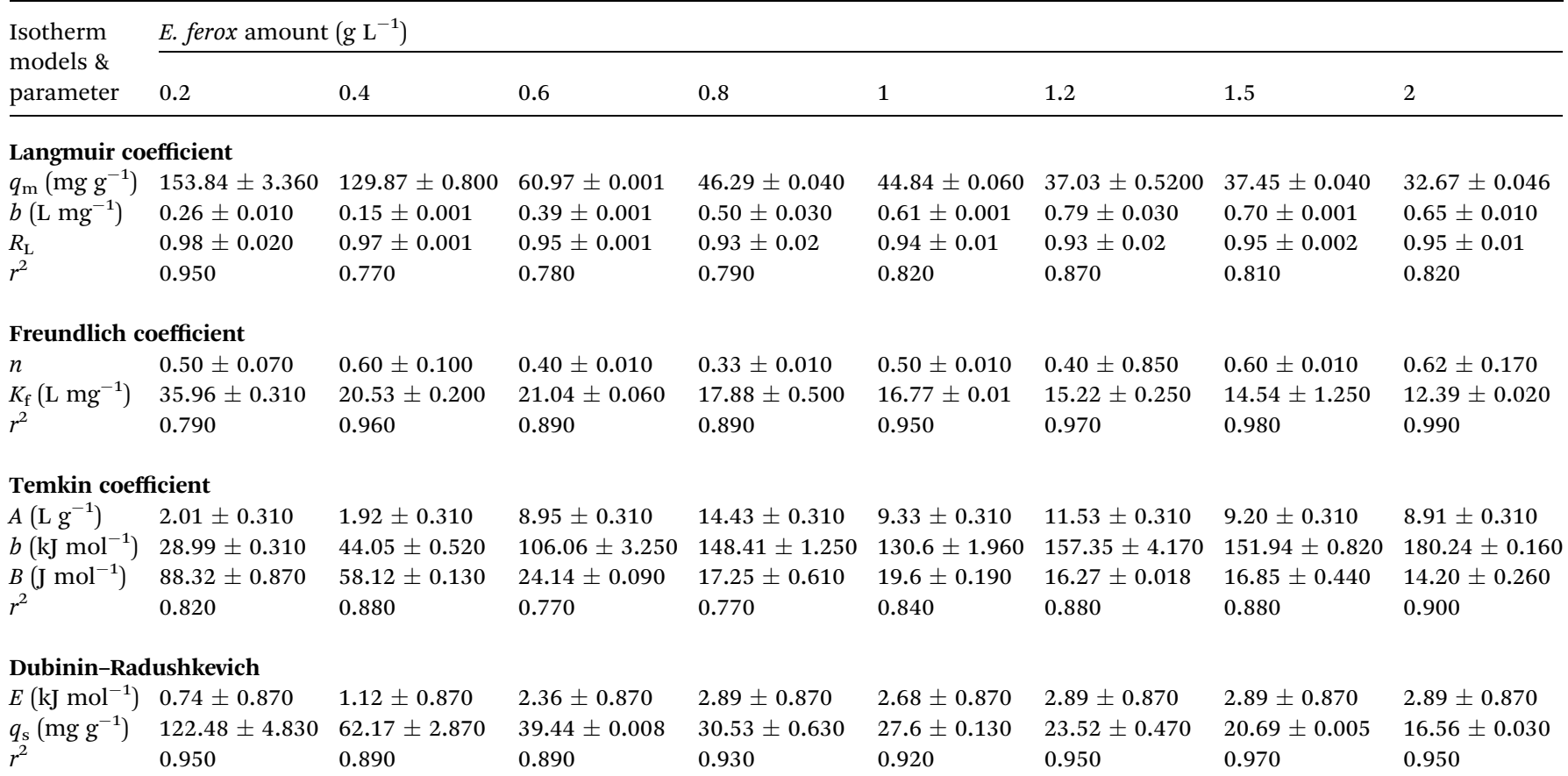


$153.84 \mathrm{mg} \mathrm{g}^{-1}$ over the entire range of adsorbent dosage from the linear plot (Fig. 5a). Another Langmuir constant, the energy of adsorption $(b)$ determines the affinity between adsorbate and adsorbent. The values of $b$ varying from $0.15-0.79 \mathrm{~L} \mathrm{mg}^{-1}$ indicates a good affinity between the dye and the adsorbent. This result supports the earlier report of adsorption of copper ions by Azadirachta indica leaf powder. ${ }^{30}$ In the Langmuir isotherm model the Hall separation factor, $R_{\mathrm{L}}$, determines the suitability of the biosorbent for a favorable adsorption process when its values lie in between 0 and $1 .{ }^{25}$ In the present study, the $R_{\mathrm{L}}$ values obtained in the range of $0.93-0.98$ within the given adsorption favorable dimension confirms the suitability of the E. ferox as a bioadsorbent for the Langmuir-type adsorption process.

The Freundlich linear plots (Fig. 5b) with a coefficient of determination, $r^{2}$ values ranging $0.79-0.99$ indicate the occurrence of a multilayer, energetically non-uniform, and heterogeneous adsorption of basic fuchsin on the surface of $E$. ferox. ${ }^{2,11}$ The calculated adsorption capacity $\left(K_{\mathrm{f}}\right)$ of the adsorbent was found to be in the range 12.39-35.96 $\mathrm{L} \mathrm{mg}^{-1}$. Further, the display of adsorption intensity $(n)$ values between $0.33-0.62$ corresponding to the condition $0<1 / n<1$ by the adsorbent implies a favorable heterogeneous adsorption process. ${ }^{\mathbf{1 1 , 2 5}}$ If the heterogeneity factor draws closer to 1 it means the surface has more heterogeneity. Therefore, heterogeneity factor with an average value of 0.49 indicates an intermediate range of heterogeneity for the adsorbent surface. ${ }^{28}$ Similarly, Freundlich isotherm was found as a better isotherm fit model for studies of dye adsorption studies onto fly ash, ${ }^{31}$ Pseudomonas putida ${ }^{32}$ and Pinus sylvestris. ${ }^{33}$

The Temkin model takes into account the effects of the interaction of the adsorbate and the adsorbing species. ${ }^{34}$ The correlation coefficient $\left(r^{2}\right)$ ranging from $0.77-0.9$ was obtained from the linear plots of $q_{\mathrm{e}}$ against $\log C_{\mathrm{e}}$ (Fig. 5c). The equilibrium binding constant $(A)$ and Temkin constant $b$ varied from 1.92-14.43 $\mathrm{L} \mathrm{g}^{-1}$ and 28.99-180.24 $\mathrm{kJ} \mathrm{mol}^{-1}$ respectively. This model assumes that the heat of adsorption of all of the molecules in the layer would decrease linearly rather than logarithmically with coverage due to adsorbate-adsorbent interactions. ${ }^{35}$ Table 4 shows that the estimated $B$ values decreases with increase coverage of the adsorbent. $B$ values being higher than 1 proposes the occurrence of electrostatic interaction between the dye and heterogeneous surface of $E$. ferox. ${ }^{19}$

Dubinin and Radushkevich model is used for distinguishing an adsorption process on a heterogeneous surface by plotting $\ln q_{\mathrm{e}}$ against $\varepsilon^{2} .^{36}$ The plots (Fig. $\left.5 \mathrm{~d}\right)$ obtained were linear $\left(r^{2}=\right.$ $0.73-0.96)$ with calculated $\mathrm{D}-\mathrm{R}$ adsorption capacity $\left(q_{\mathrm{s}}\right)$ values ranging from 16.56 to $122.48 \mathrm{mg} \mathrm{g}^{-1}$. The mean free energy of adsorption $(E)$ has small values in the range of 0.74 to $2.89 \mathrm{~kJ}$ $\mathrm{mol}^{-1}$ (Table 4) indicating that the adsorption process is nearly spontaneous. ${ }^{11}$ Also, the $K_{\text {ad }}$ values below 1 implies the surface heterogeneity of $E$. ferox. ${ }^{19}$

3.2.4 Effects of contact time and adsorption kinetics. The effects of different interactive times (20-160 $\mathrm{min}$ ) on the adsorption process was investigated by varying the biomaterial amount (0.2-2 $\left.\mathrm{g} \mathrm{L}^{-1}\right)$ with a constant adsorbate concentration of $40 \mathrm{mg} \mathrm{L}^{-1}$ at $308 \mathrm{~K}$. Fig. 6 shows the calculated $q_{t}$ values of different kinetic models along with the experimental $q_{t}$ values

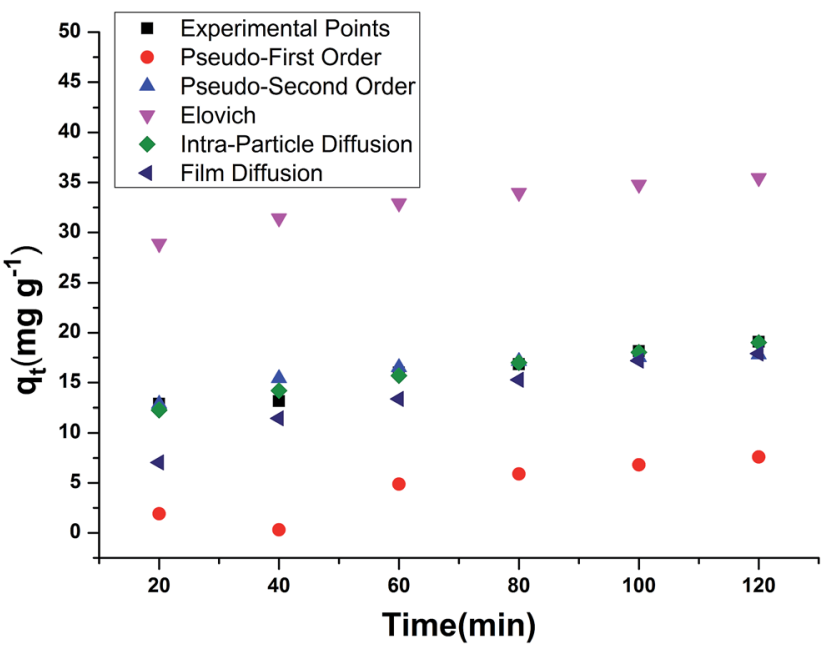

Fig. 6 General kinetic plots of experimental and calculated model points.

against time $(t)$ to compare the fitting of the models to the experimental plot. It was observed that BF adsorption on $E$. ferox reached an equilibrium state in 120 minutes. The initial 20 minutes witnessed a rapid dye removal rate due to initial availability of a large surface area, but with an increase in time the rate of adsorption slowed down. The study showed that the time needed to acquire equilibrium state was 120 minutes for each adsorbent amount. The relatively short equilibrium time of 120 minutes points out that the negatively charged E. ferox has strong affinity for the dye cations as confirmed by the FTIR results. Thereby, the results suggest that the adsorbent load had a nugatory influence on the time required for reaching equilibrium condition, but increasing the contact time increases the adsorption capacity until equilibrium is reached. ${ }^{38}$ In the present study, five different kinetic models have been applied to develop the understanding of sorbate-sorbent interactions, adsorption kinetics and controlling mechanisms such as chemical reaction, diffusion control processes, mass transfer and rate-limiting step. The experimentally obtained adsorption kinetics data were fitted to the kinetic models. The values obtained for the different kinetic parameters along with the correlation coefficient are given in Table 5 .

In the pseudo first order reaction model, the computation of the adsorption rate constant $k_{1}$ was done by plotting $\log \left(q_{\mathrm{e}}-q\right)$ against $t$ for a constant concentration of BF $\left(40 \mathrm{mg} \mathrm{L}^{-1}\right)$ with different $E$. ferox amount as shown in Fig. 7a. The values of the experimentally obtained adsorption capacity $\left(q_{\mathrm{e}}\right)$ and that of rate constant $k_{1}$ are given in Table 5. Even though all the plots showed good linearity with correlation coefficient $\left(r^{2}\right)$ values ranging from $0.87-0.96$, the experimental ' $q$ e' values at equilibrium did not agree with the calculated values of adsorption capacity. The disagreement between the experimental and calculated $q_{\mathrm{e}}$ value indicates the sorption kinetics involved in adsorption of $\mathrm{BF}$ dye on to E. ferox do not follow pseudo-first order kinetic model. ${ }^{3,11}$ Therefore, pseudo second order model was applied by plotting $t / q_{t}$ versus $t$ (Fig. 7b). Table 5 shows that unlike the pseudo first order model, the calculated ' $q_{\mathrm{e}}$ ' values 
from the pseudo second order model were similar to the experimental values. The $r^{2}$ values $(0.86-0.97)$ were closer to unity showing the predominance of this model in the adsorption process. The result indicates that the adsorption of dye on E. ferox surface follows the pseudo second order kinetic model with chemisorption adsorption mechanism. ${ }^{\mathbf{1 1 , 3 9}}$

The plots $q_{t}$ versus $\ln t$ (Fig. 7c) were plotted to verify the applicability of the Elovich equation to kinetic sorption study of E. ferox. This model is utilized for studying the chemisorption processes on a heterogeneous surface. ${ }^{35}$ Therefore, the linear plots with correlation coefficients varying from $0.8-0.92$ suggest that this model can be used to describe chemisorption adsorption of BF dye on the heterogeneous surface of E. ferox. The desorption constant $(\beta)$ varied from $3.67-29.37 \mathrm{~g} \mathrm{mg}^{-1}$. The initial adsorption rate $(\alpha)$ was found to elevate from $0.012-$ $0.356 \mathrm{mg} \mathrm{g}^{-1} \mathrm{~min}^{-1}$ on increasing the E. ferox amount $(0.2-2 \mathrm{~g}$ $\left.\mathrm{L}^{-1}\right)$. The increase in initial adsorption rate due to increase in adsorbent amount can be attributed to the availability of larger surface area for adsorption. ${ }^{28}$

Investigation of the diffusion process and to verify the influence of mass transfer resistance on the binding of basic fuchsin to $E$. ferox, the intraparticle diffusion model was applied. The intra-particle diffusion constant $k_{\mathrm{p}}\left(\mathrm{mg} \mathrm{g}^{-1}\right.$ $\left.\min ^{-0.5}\right)$ was obtained from the linear plots of $q_{t}\left(\mathrm{mg} \mathrm{g}^{-1}\right)$ versus square root of time. The values of $k_{\mathrm{p}}$ varied from $1.03-8.38 \mathrm{mg}$ $\mathrm{g}^{-1} \mathrm{~min}^{-1 / 2}$. The plots failed to pass through the origin (Fig. $7 \mathrm{~d}$ ) and had significant intercept values (Table 5) implying that the model would not solely limit the overall adsorption kinetics and intraparticle diffusion might have little role to play in the overall kinetics.

The liquid film diffusion model was used in this study to investigate the role of the transport of dye cations from the liquid phase up to the solid phase boundary of E. ferox. The liquid film diffusion constant, $k_{\mathrm{fd}}$, was in the range of $0.01-$ $0.03 \mathrm{~min}^{-1}$ (Table 5). The linear plots of $-\ln (1-F)$ vs. $t$ (Fig. 7e) had very small intercepts and since the intercept values were related to the thickness of the boundary layer, it was likely that the dye cations had to pass through a comparatively thin surface layer of the liquid phase before being adsorbed on the biosorbent surface..$^{28,40}$ It would imply that the kinetics of the sorption process could have been influenced appreciably by diffusion of the dye cations across the liquid film on the particle surfaces. ${ }^{41}$

3.2.5 Effect of temperature and thermodynamic study. The effects of temperature on the adsorption capacity of $E$. ferox and percentage removal of dye were studied by varying the temperature from 298 to $313 \mathrm{~K}$. A decrease in the adsorption capacity and dye percentage removal was recorded for an increase in the temperature. This trend was observed for all the adsorbate concentration variation (10-40 $\mathrm{mg} \mathrm{L}^{-1}$ ) for a bioadsorbent amount of $2.0 \mathrm{mg} \mathrm{g}^{-1}$. The adsorbent at an optimized temperature of $298 \mathrm{~K}$ exhibited a maximum adsorption of $97.40 \%$ with

Table 5 Kinetic parameter values of adsorption of BF on E. ferox at $308 \mathrm{~K}$ (dye $=40 \mathrm{mg} \mathrm{L}^{-1}$ ) (mean \pm standard error)

\begin{tabular}{|c|c|c|c|c|c|c|c|c|}
\hline \multirow{2}{*}{$\begin{array}{l}\text { Kinetic } \\
\text { models \& } \\
\text { parameter }\end{array}$} & \multicolumn{8}{|c|}{ E. ferox amount $\left(\mathrm{g} \mathrm{L}^{-1}\right)$} \\
\hline & 0.2 & 0.4 & 0.6 & 0.8 & 1 & 1.2 & 1.5 & 2 \\
\hline$q_{\mathrm{e}}\left(\mathrm{mg} \mathrm{g}^{-1}\right)$ & $78.6 \pm 0.21$ & $53.41 \pm 0.8$ & $35.63 \pm 0.07$ & $36.57 \pm 0.13$ & $36.08 \pm 0.5$ & $33.87 \pm 0.87$ & $16.71 \pm 0.27$ & $11.35 \pm 0.007$ \\
\hline$k_{1}\left(\min ^{-1}\right)$ & $0.014 \pm 0.31$ & $0.009 \pm 0.001$ & $0.01 \pm 0.001$ & $0.019 \pm 0.04$ & $0.021 \pm 0.001$ & $0.03 \pm 0.003$ & $0.02 \pm 0.001$ & $0.021 \pm 0.001$ \\
\hline & 0.950 & 0.960 & 0.940 & 0.910 & 0.870 & 0.940 & 0.950 & 0.950 \\
\hline
\end{tabular}

Pseudo-second order kinetic

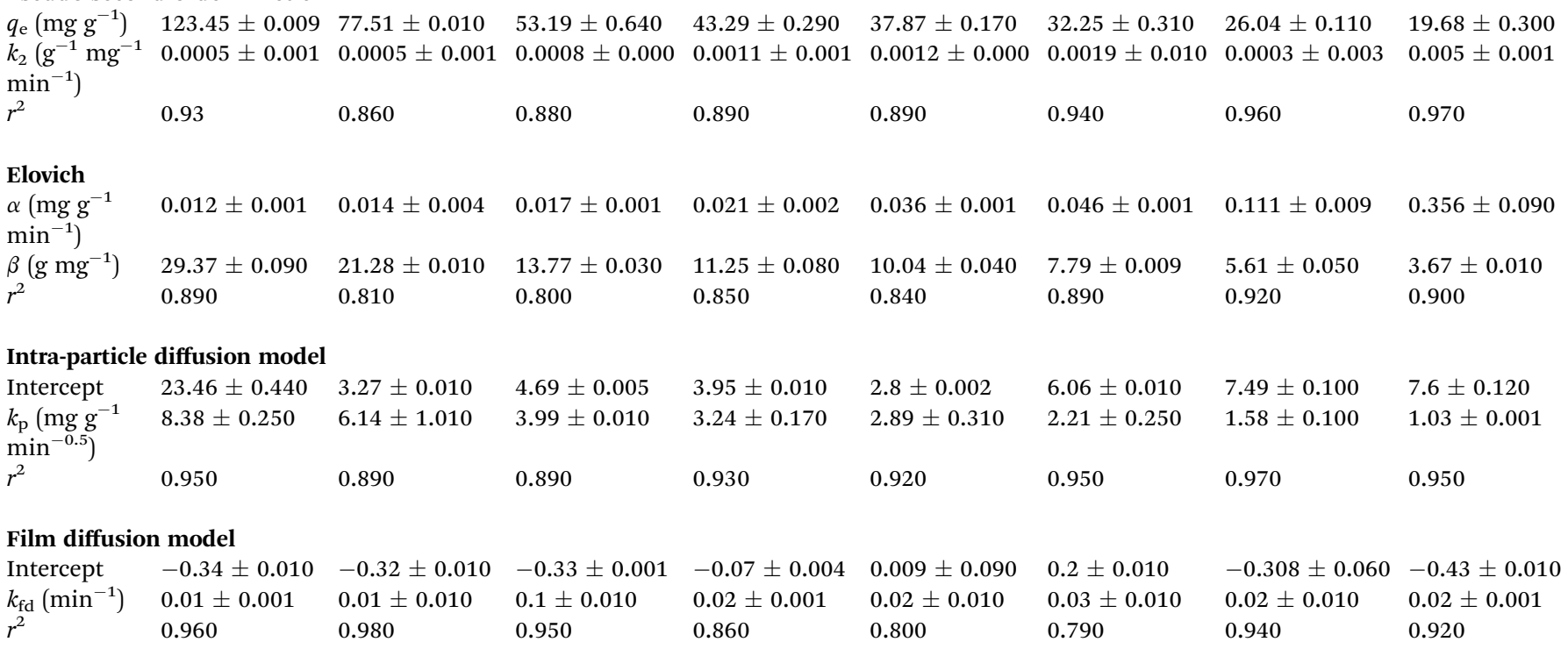



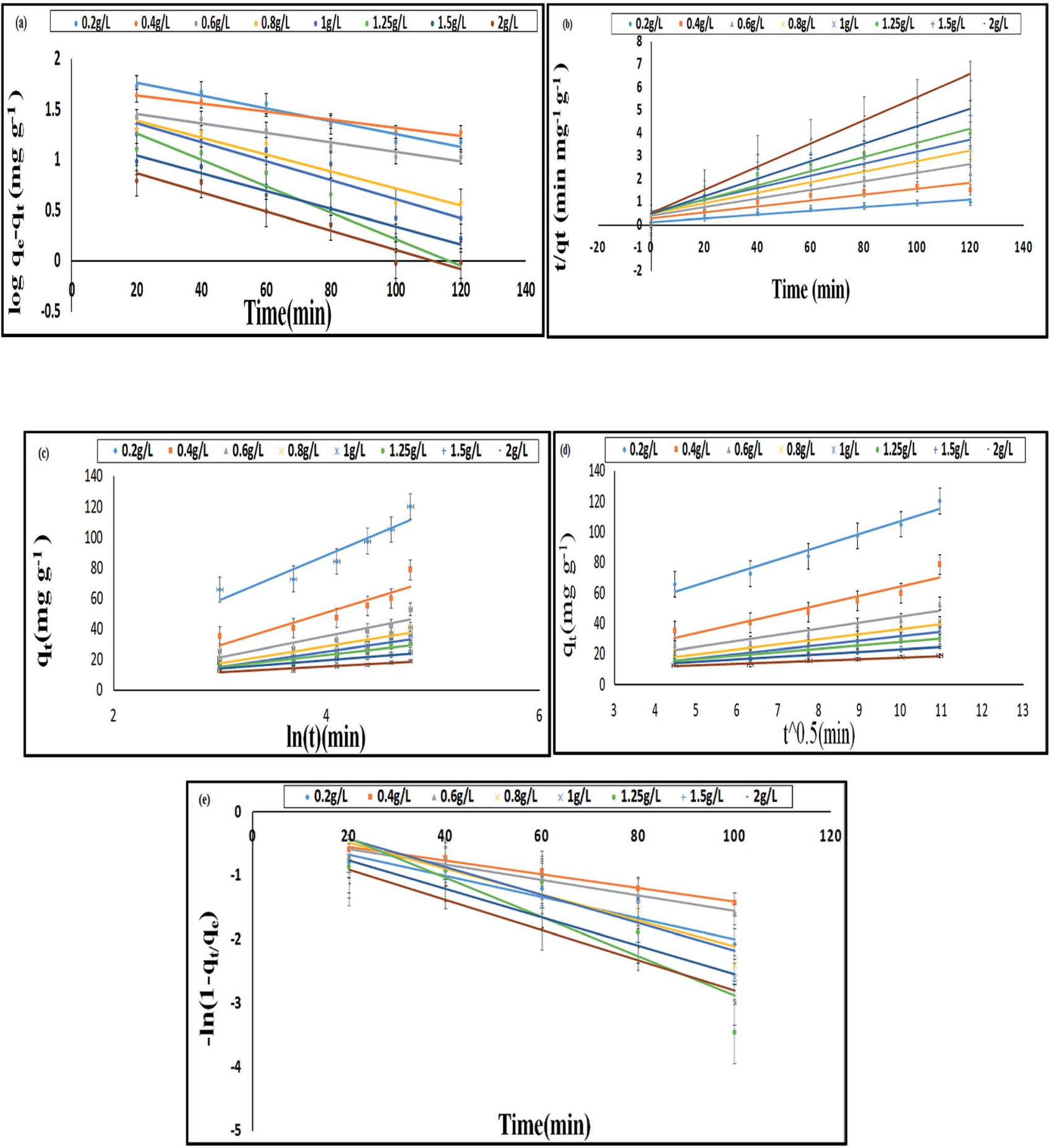

Fig. 7 Kinetic models for BF adsorption on E. ferox: (a) pseudo first order; (b) pseudo second order; (c) Elovich; (d) intra-particle diffusion; (e) film diffusion (experimental conditions: initial BF concentration $=40 \mathrm{mg} \mathrm{L}^{-1}$, temperature $=308 \mathrm{~K}, \mathrm{pH}=6$ ) (mean \pm standard error).

an adsorption capacity of $19.5 \mathrm{mg} \mathrm{g}^{-1}$. The decrease in the adsorption of the dye amount with an increase in temperature indicates the exothermic nature of the adsorption process. ${ }^{19}$

The thermodynamic parameters were computed from the plots of $\log q_{\mathrm{e}} / C_{\mathrm{e}}$ against $1 / T$ to evaluate the thermodynamics of adsorption and to work out the feasibility of E. Ferox as a biosorbent for the dye. Table 6 shows that the $\Delta G$ values decreased with an increase in temperature for a constant and varied adsorbate concentration.

The decline in $\Delta G$ values describes the spontaneity of the adsorption process. The negative $\Delta G$ and $\Delta H$ values represent the adsorption behaviour of E. ferox particles as a feasible, spontaneous and exothermic process. The decrease in $\Delta S$ values from -20.25 to $-140.34 \mathrm{~J} \mathrm{~mol}^{-1} \mathrm{~L}^{-1}$ indicates diminishing randomness at the solid-solution interface following 
Table 6 Thermodynamic parameters for adsorption of BF on E. ferox for different concentrations of $\mathrm{BF}$ at $298 \mathrm{~K}$ to $313 \mathrm{~K}$, amount of $E$. ferox $\left(2.0 \mathrm{~g} \mathrm{~L}^{-1}\right)$

\begin{tabular}{lllllll}
\hline & & & \multicolumn{5}{c}{$-\Delta G\left(\mathrm{~kJ} \mathrm{~mol}^{-1}\right)$} \\
\cline { 5 - 7 } $\begin{array}{l}\mathrm{BF} \\
\left(\mathrm{mg} \mathrm{L}^{-1}\right)\end{array}$ & $\begin{array}{l}-\Delta H \\
\left(\mathrm{~kJ} \mathrm{~mol}^{-1}\right)\end{array}$ & $\begin{array}{l}-\Delta S \\
\left(\mathrm{~J} \mathrm{~mol}^{-1} \mathrm{~L}^{-1}\right)\end{array}$ & $298 \mathrm{~K}$ & $303 \mathrm{~K}$ & $308 \mathrm{~K}$ & $313 \mathrm{~K}$ \\
\hline 10 & -14.39 & -20.25 & -8.36 & -8 & -7.9 & -7.26 \\
20 & -48.57 & -136.11 & -8.26 & -7.32 & -7.2 & -6.76 \\
30 & -49.73 & -140.34 & -8.15 & -6.64 & -6.5 & -6.26 \\
40 & -37.08 & -100.08 & -8.05 & -5.96 & -5.8 & -5.76 \\
Mean & -37.44 & -99.19 & -8.2 & -6.98 & -6.85 & -6.51
\end{tabular}

adsorption of the dye. Earlier studies on thermodynamic nature of dye adsorption state that under favourable conditions, both physisorption and chemisorption processes may occur simultaneously or alternately. ${ }^{42}$ Hence, $\Delta H$ values ranging from -14.398 to $-49.73 \mathrm{~kJ} \mathrm{~mol}^{-1} \mathrm{~K}^{-1}$ suggests the probability of occurrence of both physisorption and chemisorption processes together in the adsorption of BF dye cations on E. ferox. ${ }^{3}$ Similar results have been reported when phenol adsorption on activated carbon was studied by Humpola et al. ${ }^{43}$

\section{Conclusion}

The results have shown that $E$. ferox residue biomass could be very effective in the removal of cationic dyes like basic fuchsin from aqueous medium. The material was stable in a wide range of $\mathrm{pH}$ and the zeta potential measurements indicated that the material develops a negative charge at $\mathrm{pH}>1.0$ and therefore is suitable for adsorptive removal of cations from water. In the present work, as basic fuchsin is unstable above $\mathrm{pH}$ 6.0, the experiments were done below this $\mathrm{pH}$ and the results are very promising.

The interactions between the biomaterial and the dye cations have been shown to involve -OH groups of the material and $\mathrm{NH} / \mathrm{NH}_{2}$ groups of the dye with likely participation of $>\mathrm{CO}$ groups of the E. ferox. The process has been found to be exothermic and spontaneous accompanied by considerable decrease in enthalpy, entropy and Gibbs energy of the process. Of the different kinetic models used, it is found that the interactions conform to a pseudo-second order model indicating that the dye cations may be held to the biomaterial surface through more than one site. The adsorption data fitted both Freundlich and Langmuir isotherms suggesting chemisorption of the dye cations on E. ferox followed by physisorption on the adsorbed layer.

\section{Abbreviations}

$E$. ferox
$q_{\mathrm{e}}$
$C_{\mathrm{o}}$
$C_{\mathrm{e}}$
$V$
$M$
$q_{\mathrm{m}}$

Euryale ferox

Adsorption capacity

Initial concentration

Final concentration

Volume of solution

Mass of the adsorbent

Monolayer adsorption capacity

$\begin{array}{ll}b & \text { Langmuir constant } \\ R_{\mathrm{L}} & \text { Hall constant } \\ n & \text { Heterogeneity factor } \\ B & \text { Temkin constant } \\ q_{\mathrm{s}} & \text { D-R monolayer adsorption capacity } \\ \varepsilon & \text { Polanyi potential } \\ k_{1} & \text { First order constant } \\ k_{2} & \text { Second order constant } \\ \alpha & \text { Initial adsorption rate } \\ \beta & \text { Desorption constant } \\ k_{\mathrm{p}} & \text { Intraparticle diffusion rate constant } \\ k_{\mathrm{fd}} & \text { Liquid film diffusion constant } \\ \Delta H & \text { Enthalpy } \\ T & \text { Absolute temperature } \\ R & \text { Gas constant } \\ \Delta S & \text { Entropy } \\ \Delta G & \text { Gibbs energy }\end{array}$

\section{Acknowledgements}

The authors are grateful to the Department of Science and Technology, Govt. of India and the Director of the Institute of Advanced Study in Science and Technology (IASST), Guwahati for financial support to execute this work. The authors are also obliged to thank the Physical Sciences Division and the Central Instrumentation facility of IASST for the help in different instrumentation work.

\section{References}

1 A. W. M. Ip, J. P. Barford and G. McKay, Chem. Eng. J., 2010, 157, 434-442.

2 A. M. Aljeboree, A. N. Alshirifi and A. F. Alkaim, Arabian J. Chem., 2014, DOI: 10.1016/j.arabjc.2014.01.020.

3 Y. Feng, F. Yang, Y. Wang, L. Ma, Y. Wu, P. G. Kerr and L. Yang, Bioresour. Technol., 2011, 102, 10280-10285.

4 Y. Tao, W. Z. Jian, J. Kui and L. Q. Jun, Chem. Res. Chin. Univ., 2006, 22, 292-296.

5 V. K. Gupta, A. Mittal, V. Gajbe and J. Mittal, J. Colloid Interface Sci., 2008, 319, 30-39.

6 E. Bayram and E. Ayranci, Environ. Sci. Technol., 2010, 44, 6331-6336.

7 G. Crini, Bioresour. Technol., 2006, 97, 1061-1085.

8 Q. Sun and L. Yang, Water Res., 2003, 37, 1535-1544.

9 B. D. Bhole, B. Ganguly, A. Madhuram, D. Deshpande and J. Joshi, Curr. Sci., 2004, 86, 1641.

10 Q. Shi, J. Zhang, C. Zhang, W. Nie, B. Zhang and H. Zhang, J. Colloid Interface Sci., 2010, 343, 188-193.

11 M. E. Haddad, J. Taibah Univ. Sci., 2015, DOI: 10.1016/ j.jtusci.2015.08.007.

12 A. K. Verma, B. K. Banerji, D. Chakrabarty and S. K. Datta, Curr. Sci., 2010, 99, 795-800.

13 R. J. Lan, J. T. Li and B. H. Chen, Int. J. Photoenergy, 2013, 2013, 1-7.

14 Official methods of analysis of AOAC International, ed. W. Horwitz, Association of Analytical Communities, Gaithersburg, MD, USA, 17th edn, 1st revision, 2002. 
15 A. O. Ayeni, F. K. Hymore, S. N. Mudliar, S. C. Deshmukh, D. B. Satpute, J. A. Omoleye and R. A. Pandey, Fuel, 2012, DOI: 10.1016/j.fuel.2012.12.078.

16 Technical Association of the Pulp and Paper Industry: Sampling and Preparing Wood for Analysis Technical Association of the Pulp and Paper Industry, TAPPI Standard T222 om-02, 2002.

17 F. F. Avelar, M. L. Bianchi, M. Gonçalves and E. G. da Mota, Bioresour. Technol., 2010, 10, 4639-4645.

18 R. Garcia, C. Pizarro, A. G. Lavin and J. L. Bueno, Bioresour. Technol., 2013, 139, 1-4.

19 O. Uner, U. Gecgel and Y. Bayrak, Water, Air, Soil Pollut., 2016, 227, 1-15.

20 N. Kohan, G. Machado, C. Jing, A. Nagardeolekar and B. M. Bujanovic, Energies, 2015, 8, 9640-9654.

21 B. Cagnon, X. Py, A. Guillot, F. Stoeckli and G. Chambat, Bioresour. Technol., 2009, 100, 292-298.

22 A. Kumar and H. M. Jena, Results Phys., 2016, 6, 651-658.

23 O. A. Ekpete and M. Horsfall, Res. J. Chem. Sci., 2011, 1, 1017.

24 R. Malik, D. S. Ramteke and S. R. Wate, Indian J. Chem. Technol., 2006, 13, 319-328.

25 S. T. Akar, Y. Y. Balk, O. Tuna and T. Akar, Carbohydr. Polym., 2013, 94, 400-408.

26 O. S. Bello, K. A. Adegoke and O. O. Akinyunni, Appl. Water Sci., 2015, DOI: 10.1007/s13201-015-0345-4.

27 N. F. Cardoso, E. C. Lima, I. S. Pinto, C. V. Amavisca, B. Royer, R. B. Pinto, W. S. Alencar and S. F. P. Pereira, J. Environ. Manage., 2011, 92, 1237.

28 S. Baruah, A. Devi, K. G. Bhattacharyya and A. Sarma, Int. J. Environ. Sci. Technol., 2016, DOI: 10.1007/s13762-016-1150-9.
29 S. V. Gokhale, K. K. Jyoti and S. S. Lele, Bioresour. Technol., 2008, 99, 3600-3608.

30 K. G. Bhattacharyya, A. Sarma and J. Sarma, Adsorpt. Sci. Technol., 2010, 8.

31 J. X. Lin, S. L. Zhan, M. H. Fang, X. Q. Qian and H. Yang, J. Environ. Manage., 2008, 87, 193-200.

32 A. Arunarani, P. Chandran, B. V. Ranganathan, N. S. Vasanthi and S. S. Khan, Colloids Surf., B, 2013, 102, 379-384.

33 O. Aksakal and H. Ucun, J. Hazard. Mater., 2010, 181, 666672.

34 M. J. Tempkin and V. Pyzhev, Acta Physicochim. URSS, 1940, 12, 217-222.

35 C. Aharoni and M. Ungarish, J. Chem. Soc., 1977, 73, 456464.

36 M. M. Dubinin and L. V. Radushkevich, Proceedings of the Academy of Sciences (USSR), 1947, 55, 331-333.

37 K. M. Rani, P. N. Palanisamy, S. Gayathri and S. Tamilselv, International Journal of Innovative Research in Science, Engineering and Technology, 2015, 4, 6845-6853.

38 Y. Feng, H. Zhou, G. Liu, G. Qiao, J. Wang, H. Lu, L. Yang and Y. Wu, Bioresour. Technol., 2012, 125, 138-144.

39 S. Lagergren, K. Sven. Vetenskapsakad. Handl., 1898, 24, 139.

40 Y. Yao, F. Xu, M. Chen, Z. Xu and Z. Zhu, Bioresour. Technol., 2010, 101, 3040-3046.

41 J. Sarma, A. Sarma and K. G. Bhattacharyya, Ind. Eng. Chem. Res., 2008, 47, 5433-5440.

42 A. Dabrowski, Adv. Colloid Interface Sci., 2001, 93, 135-224.

43 P. Humpola, H. Odetti, A. Fertitta and J. Vicente, J. Chil. Chem. Soc., 2013, 58, 1541-1544. 